\title{
8
}

\section{im

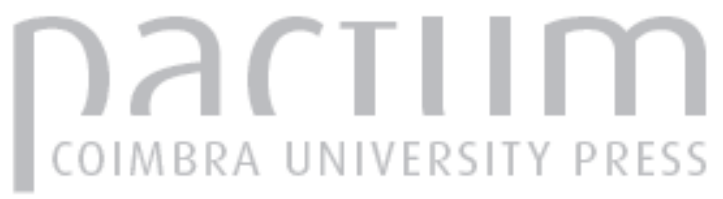

\section{[Recensão a] Giuseppe Marcocci e José Pedro Paiva, História da Inquisição Portuguesa 1536-1821}

\author{
Autor(es): $\quad$ Voss, Rita Ribeiro
}

Publicado por: Imprensa da Universidade de Coimbra

URL persistente:

URI:http://hdl.handle.net/10316.2/43255

DOI:

DOI:https://doi.org/10.14195/0870-4147_48_19

Accessed : $\quad$ 26-Apr-2023 12:57:13

A navegação consulta e descarregamento dos títulos inseridos nas Bibliotecas Digitais UC Digitalis, UC Pombalina e UC Impactum, pressupõem a aceitação plena e sem reservas dos Termos e Condições de Uso destas Bibliotecas Digitais, disponíveis em https://digitalis.uc.pt/pt-pt/termos.

Conforme exposto nos referidos Termos e Condições de Uso, o descarregamento de títulos de acesso restrito requer uma licença válida de autorização devendo o utilizador aceder ao(s) documento(s) a partir de um endereço de IP da instituição detentora da supramencionada licença.

Ao utilizador é apenas permitido o descarregamento para uso pessoal, pelo que o emprego do(s) título(s) descarregado(s) para outro fim, designadamente comercial, carece de autorização do respetivo autor ou editor da obra.

Na medida em que todas as obras da UC Digitalis se encontram protegidas pelo Código do Direito de Autor e Direitos Conexos e demais legislação aplicável, toda a cópia, parcial ou total, deste documento, nos casos em que é legalmente admitida, deverá conter ou fazer-se acompanhar por este aviso.

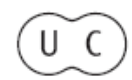




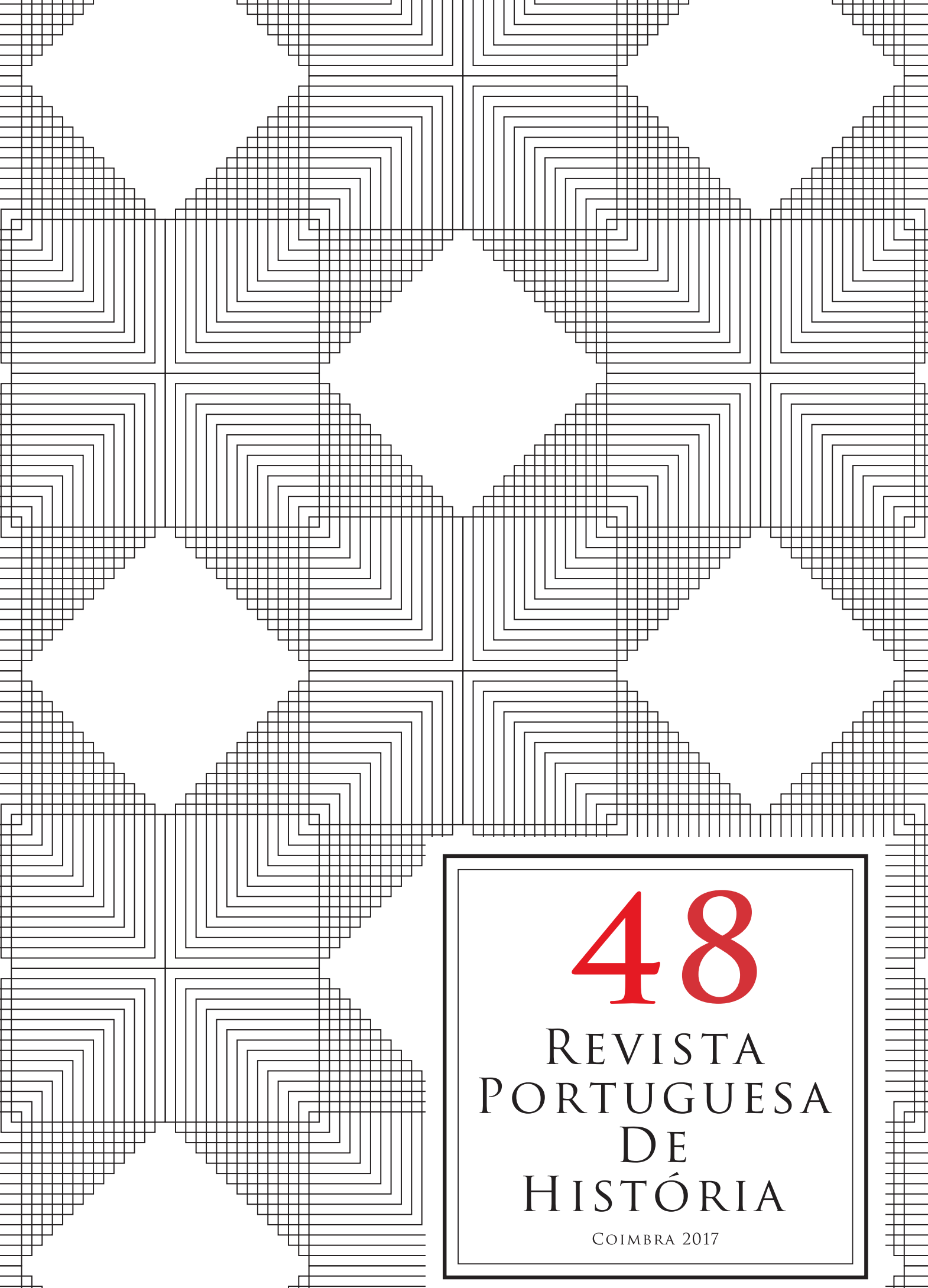




\section{Giuseppe Marcocci e José Pedro Paiva, História da Inquisição Portuguesa 1536-1821. Lisboa, A Esfera dos Livros, 2016. 608 p.}

A primeira edição do livro História da Inquisição Portuguesa, escrito por Giuseppe Marcocci e José Pedro Paiva, foi publicado em Lisboa no ano de 2013 pela editora A Esfera dos Livros e em outubro de 2016 foi lançada a segunda edição revista.

Marcocci é historiador e professor na Università degli Studi dela Tuscia na Itália, especializado em História Política, Cultural e Religiosa da Península Ibérica, autor do livro A consciência de um império: Portugal e o seu mundo, sécs. XV-XVII, publicado em 2012 em Coimbra. Paiva é historiador e professor na Universidade de Coimbra e investigador no Centro de Estudos de História Religiosa; concentra-se na área de História Religiosa e Cultural em Portugal. Entre suas produções bibliográficas, destacam-se os livros Bruxaria e superstição num país sem "caça às bruxas", lançado em Lisboa em 1997; Os bispos de Portugal e do império (1495-1777) lançado em Coimbra em 2006; Baluartes da Fé e da disciplina. O enlace entre a Inquisição e os bispos em Portugal (1536-1750), publicado em Coimbra, em 2011.

A História da Inquisição Portuguesa é uma obra de fôlego e uma referência importante para os estudos sobre a Inquisição portuguesa. Os autores, à luz de farta documentação sobre todo o período de existência da Inquisição, analisam temas recorrentes nos estudos historiográficos sobre o tema, ampliando o sentido e o alcance acadêmicos de suas discussões. Ao imbricar aspetos econômicos, culturais, sociais, políticos e religiosos, o livro leva o leitor a compreender a Inquisição como um fenômeno histórico complexo e, por isso, arredio a explicações monocausais. Mas há um aspeto que se destaca na obra, o delineamento da instituição como sistema jurídico, como um aparato administrativo regido por normas e controles sociais cuja originalidade estava na sua organização em rede.

Esse delineamento institucional concebeu estratégias de dominação social e política que configuraram a unidade identitária nacional portuguesa a partir da religião. No entanto, essa busca de uma unidade religiosa é uma obviedade que não daria conta, por si só, de explicar a continuidade do Tribunal do Santo Ofício, sua influência política e legitimidade social que possibilitaram sua longa existência. Para compreender esse sistema de dominação, os autores trilham um caminho pouco tratado na historiografia que é o modo pelo qual a poderosa instituição se estruturou: como um sistema constituído por normas, regras, cargos, salários e uma tessitura organizacional com autonomia financeira e administração rotineiros. Sem a estruturação de um sistema com entrada de 
recursos financeiros, de processos acusatórios e com condenações juridicamente embasadas, a Inquisição portuguesa não teria conseguido sobreviver por quase três séculos.

Com essa intenção, Marcocci e Paiva explicitam que a síntese histórica que eles empreenderam está centrada no Tribunal, isto é, na compreensão de sua evolução desde sua instalação; no seu desenvolvimento até a sua consolidação com a implementação de seus vários regimentos; e, também, na compreensão de seus contornos ideológicos que configuraram o sistema jurídico-religioso como uma instituição poliédrica "com impactos enormes na sociedade portuguesa, na qual assumiu uma vocação hegemônica que respondia à ordem religiosa e cultural em transformação, com repercussões em todos os âmbitos" (p. 15).

Mas o estabelecimento da Inquisição, como se pode ler nas páginas iniciais do livro, não era consensual antes de seu estabelecimento. Os jogos de poder entre os atores políticos, a coroa e os bispos, deixam entrever um processo marcado por posições antagônicas quanto à instalação do Tribunal do Santo Ofício em território português. A tensão se explicita na existência de duas tendências na corte, uma humanista influenciada por Erasmo de Roterdão, contrária à existência do Tribunal, e outra conservadora, que reagia às novidades que se introduziam no mundo renascentista trazidas pelo pensamento científico e pela reforma e que via no estabelecimento de uma nova forma de pensar as relações humanas e a religião uma ameaça ao dogma católico e à centralidade espiritual no domínio social, cultural e político em Portugal.

Fosse ou não possível outro o caminho histórico a percorrer, o resultado da tensão foi a instalação do Tribunal em Portugal no reinado de D. João III, em pleno Renascimento Português, na cidade de Évora, com a bula Cum ad nil magis do Papa Clemente VII. Seus tribunais acabaram se estabelecendo no território português em três regiões geograficamente estratégicas, Lisboa, Coimbra e Évora, além de sua forte atuação em Goa, na Índia, e estender seu controle na África e Brasil através de visitações inquisitoriais.

A instituição inicialmente se organizou em torno de um Conselho de Deputados, cujos membros eram ligados aos teólogos da Corte. O Conselho se responsabilizava por arrolar os delitos a serem julgados pelo Santo Ofício. Entre eles, além da preocupação com a ameaça da disseminação de crenças luteranas, estavam previstas heresias como bigamia, bruxaria, elementos da religiosidade popular e toda sorte de transgressões privadas pecaminosas, de ordem íntima e mesmo espiritual dos habitantes do reino, revelando sua face totalitária. Mais tarde, essa forma deliberativa coletiva foi substituída pela centralização de poder no inquisidor geral, com a nomeação do D. Henrique em 1539. 
O Tribunal era, sobretudo, uma instituição eclesiástica com participação da coroa, ainda que esta fosse concorrente à hegemonia religiosa alcançada no interior da correlação de forças políticas do Estado. Assim a instituição adquiriu uma certa autonomia como sistema punitivo em relação ao poder régio, e às outras justiças, que tendia a sobrepô-lo. Essa assimetria política seria revertida, dois séculos depois da instalação do tribunal do Santo Ofício, em favor da monarquia com as reformas do Marquês de Pombal, no século XVIII, ao subordinar o Tribunal ao Estado, depois de proibir a discriminação entre cristãos-novos e cristãos-velhos, removendo assim o motivo primordial de sua existência.

A política inquisitorial era persecutória contra as minorias em geral, mas teve como alvo privilegiado, como o coração mesmo da Inquisição, a perseguição aos cristãos-novos. O estabelecimento da Inquisição foi o desfecho de uma situação social que se arrastava desde 1496 quando os judeus foram expulsos do território português e, no ano seguinte, quando foram batizados à força. A partir daí se estabeleceram, no corpo da sociedade portuguesa, dois tipos de habitantes do reino os chamados cristãos-novos e os cristãos-velhos. Os primeiros foram estigmatizados por sua antiga religião que, na verdade, não parecia ter sido abandonada, uma vez que muitos continuavam a professar a antiga fé como cripto-judeus. Acrescenta-se a isso outro motivo de desconfiança aos olhos da população. Além das razões de ordem religiosa, havia um sentimento de ódio e de antipatia aos arrendadores de impostos e aos ricos comerciantes, ocupações exercidas maioritariamente de judeus.

A imensa maioria de cristãos-velhos tinha pouca ou nenhuma instrução e ficou submetida aos sermões populares e a prédicas dominicais de nítida judeofobia, que já se verificavam em Portugal e na Espanha desde o século XV ou ainda anteriormente, desde o século XIII, em toda a Europa desde a publicação dos cânones antijudaicos do Concílio de Latrão. A transformação de judeus em cristãos-novos passou a ser um motivo de discriminação social no país lusitano talvez pelo fato da política de integração imposta por D. Manuel, nos tempos da conversão forçada, ter sido grandemente rejeitada por parte do clero e pela população submetida às influências dos predicadores. Os cristãos-novos se tornariam, por esse motivo, alvos privilegiados como inimigos da fé católica, como aconteceu em 1506 num episódio sangrento conhecido como Massacre de Lisboa que levou milhares deles à morte por linchamento.

No sentido teológico, propriamente dito, para a Igreja os judeus eram uma ameaça contra o dogma maior da Igreja Católica, a Santíssima Trindade. Amaior oração judaica, o Shema, é uma declaração da unicidade e indivisibilidade de Deus e o conteúdo de um de seus livros mais importantes, uma mistura de texto 
sagrado e guia de orientação para a vida, o Talmud, reforçava a ideia de uma religião contrária à idolatria, o que afrontava o costume católico de cultuar santos e a Virgem Maria.

Mas o clero não atingia a mente popular com disputas de natureza teológica, tão comuns no século XV. As disputas eram esotéricas pois o acompanhamento e julgamento dos embates entre estudiosos cristãos e judeus dependiam de um nível intelectual elevado. O antijudaísmo da população foi construído discursivamente por meio da demonização de comportamentos judaicos estereotipados de que eram acusados como o sacrifício de crianças para o Shabbat e a profanação de hóstias em igrejas, crenças já disseminadas em toda a Europa durante a Idade Média e que iriam perdurar ainda por séculos na literatura e propaganda antissemitas.

A organização jurídica e organizacional sob a qual o Tribunal realizou a sua função persecutória deveu-se ao Cardeal-Rei D. Henrique, com seu forte sentimento antijudaico. Como inquisidor-geral, logo no início da atuação do Tribunal do Santo Ofício, foi de vital importância para a organização e consolidação da Inquisição como um sistema jurídico essencialmente cristão, cujas condenações se amparavam na confissão e no segredo processual. Isto é, a confissão "sincera" dos acusados dependia que a acusação do delito, geralmente feita por um delator que também havia sido delatado por outra pessoa, não fosse conhecida pelo herético. Além disso, a prática de quebra de sigilo sacramental da confissão tornou-se comum nesse sistema de delação, o que reforçava mais ainda o segredo processual. $\mathrm{O}$ inquisidor partia do pressuposto de que a culpa era certa e que a delação era verdadeira. Portanto, a confissão era um bem para o acusado que teria a oportunidade de se arrepender de suas heresias e garantir o perdão eterno.

Os meios de obtenção da confissão variavam segundo a predisposição do acusado em confessar, isto é, em acertar a acusação do delator e, também, se e o quanto se arrependia. De qualquer forma, a pena era certa, já que se partia sempre da presunção da culpa. Esta poderia ser leve ou grave, indo de penitências, como rezas de arrependimento, ao degredo ou o uso de hábitos perpétuos, até o relaxamento ao braço secular. A condenação e a pena estavam sempre intimamente ligadas à delação, à confissão e ao arrependimento. Em suma, o inquisidor, concentrando e conjugando em si o papel de investigar e o poder de julgar, conduzia o processo de modo a confirmar uma acusação desconhecida pelo réu, fruto de delação.

Ainda que aos olhos do direito racional e natural, já discutida pela filosofia política do século XVI, essa penalização fosse injusta, seus aspetos formais foram regulamentados por regimentos que conferiam ao sistema, contraditoriamente, 
sua face instrumental-legal. O primeiro regimento da Inquisição foi em 1552, a cargo de religiosos da confiança do inquisidor geral, D. Henrique, que fixou as penas e as regras de funcionamento do Tribunal. Esse regimento, regulamentou as competências dos ministros, dos fiscais e dos deputados e, também, a ascensão ao cargo de inquisidor e seu perfil, constituindo soldos, carreiras e promoções. As visitas inquisitoriais foram regulamentadas proporcionalmente ao tamanho das localidades a serem visitadas. Também foram estipuladas normas processuais judiciais quanto à prisão do acusado com base no depoimento de uma só testemunha e no uso do já referido segredo processual. Estas seriam posteriormente criticadas pelos opositores do regime, como normatização que levavam a práticas desumanas e afronta a ideais humanistas. Essa ordenação jurídica também foi objeto constante de reclamações de cristãos-novos à Santa Sé durante os séculos de existência do Tribunal, gerando perdões gerais que atendiam mais à conveniência da coroa para obter receita em tempos críticos, por isso, foram esporádicos, embora esse não tenha sido, segundo os autores o motivo do estabelecimento da Inquisição em Portugal. Também havia uma previsão regimental do recrutamento de confessores intencionou a formação de uma rede de controle espiritual sobre a população, que era central no sistema punitivo inquisitorial baseado na confissão e na delação.

O livro foi organizado em cinco partes, que correspondem aos principais períodos da Inquisição Portuguesa, com o objetivo de abranger todo o período de vida do Tribunal do Santo Ofício, de 1536 a 1821. A primeira parte abarca o período de 1536 a 1605 que aborda o seu surgimento, seu desenvolvimento bem como a regulamentação e organização administrativa iniciais até a sua primeira grande crise com o perdão geral aos cristãos-novos em 1605. O regimento de 1552 já considerado anteriormente, no que se refere à especificação dos crimes, arrolou os vários tipos de heresia como bigamia, bruxaria, elementos da religiosidade popular e toda sorte de transgressões privadas pecaminosas, de ordem íntima e mesmo espiritual dos habitantes do reino, revelando sua face totalitária. Já o regimento de 1570 regulamentou o confisco de bens e o uso da receita. O confisco não visava dar suporte financeiro ao Tribunal, muitas vezes os bens de condenados, quando havia, eram utilizados para sustentar os próprios presos nos cárceres e tantos outros foram assistidos pelas Misericórdias.

A segunda parte corresponde ao período de 1605 a 1681, ao tempo em que a Inquisição foi mais brutal contra os cristãos-novos acusados de judaísmo, logo após o perdão geral. Os regimentos de 1613 e 1640 regulamentaram ainda com mais precisão os aspetos processuais da Inquisição, a sua organização mais consolidada, as suas praxes que são analisadas e compreendidas a partir do processo do padre jesuíta António Vieira. Por fim, os autores abordam a 
segunda grande crise da Inquisição portuguesa que porá um termo provisório ao Tribunal entre 1674 e 1681.

A terceira parte do livro aborda o período de transformação da Inquisição em sua fase barroca entre 1681, quando o Tribunal é restabelecido depois de sua suspensão de dois anos, e 1755, quando o terremoto de Lisboa danificou seriamente o Palácio da Inquisição. Os autores se propõem a dar ênfase aos "jogos de luz e sombra", isto é, à correlação de poder e de prestígio entre os atores envolvidos na legitimação da Inquisição.

Destaca-se nessa parte um capítulo sobre a espetacularização da condenação e da execução da pena representada nos Autos de Fé, o principal cerimonial da Inquisição. Este refletia a estrutura rígida da instituição e de uma sociedade submetida ao dogma, a uma pedagogia das tradições católicas de maneira exemplar: a punição à heresia.

Os sermões, que também são abordados na terceira parte, são a expressão da violência simbólica promovida pelo clero sobre a sociedade. Como um grande rio com seus afluentes, os discursos religiosos irrigavam toda a sociedade inculcando modos de ser e de pensar na população que retroativamente se nutria do ódio que sustentava o próprio sistema inquisitorial: "O Santo Ofício era um corpo aberto ao contexto político, social e religioso em que atuava, manipulando-o e sendo por ele manipulado" (p. 287). Com o gradual arrefecimento da perseguição aos cristãos-novos, a Inquisição voltou-se para outras heresias como o molinosismo, o sigilismo e a maçonaria e para o controle da vida espiritual mais íntima das pessoas e também para práticas religiosas populares. Mas o Tribunal já não agia com a mesma força e nem as condenações com morte aconteciam do modo público, foram se restringindo a salas para pequenas audiências. Em sua, já a instituição já não tinha a mesma importância.

A quarta parte trata da Inquisição no período das reformas pombalinas, entre 1755 e 1820, quando a instituição chega a seu termo. Se a Inquisição submeteu muitas vezes o poder temporal ao religioso, será nesse período que Sebastião José de Carvalho e Melo, o Marquês de Pombal, promoverá a sua adaptação a mera instância judiciária do Estado. Além desse poderoso peso contrário às forças do Santo Ofício sobre o poder temporal, outro fator de desestabilização tardia da Inquisição foram os ideais da Revolução Francesa. Portugal amargou uma péssima reputação em razão do anacronismo e crueldade de suas instituições que sobreviviam às duras penas nos primeiros anos do século XIX, já submetida ao poder temporal. O regimento de 1774, por fim, descaracterizou a instituição pré-anunciando o seu fim ao abolir institutos jurídicos importantes como o segredo processual, o testemunho de uma só pessoa contra o condenado e a prática da tortura, além de, e o que é mais importante, a proibição de sequer 
chamar alguém de cristão-novo, eliminando assim seu alvo, principal inimigo e razão de existência da Inquisição.

A quinta e última parte trata da historiografia sobre a Inquisição e de questões relativas às razões de seu estabelecimento e de sua longa duração à revelia das transformações mundiais. Essa parte ressalta duas tendências acadêmicas, uma para a explicação sociocultural, que acentua os contornos religiosos da existência da instituição, e outra tendência que aponta para o interesse meramente monetário e financeiro da coroa e do clero, dado o perfil socioeconómico de judeus e cristãos-novos na sociedade portuguesa. Por fim, as últimas páginas do livro refletem sobre o papel da revolução liberal e de seu secularismo para o fim da Inquisição.

Em síntese, o Tribunal do Santo Ofício foi um sistema jurídico de delação-condenação-punição com capacidade financeira e administrativa e um enorme poder religioso, que se sustentou sobre os seguintes alicerces: 1) hegemonia confere uma relativa autonomia na gestão administrativa e, ao longo do tempo, financeira; 2) normatização do cotidiano - estabelece cargos, salários e funções; 3) ordenação legal - punição aos hereges, em sua grande maioria cristãos-novos, com base no segredo processual, no testemunho de uma só pessoa e na quebra do segredo sacramental da confissão; 4) rede de confessores para o controle espiritual; 5) de rede de familiares com cargos honoríficos para o controle social; 6) censura e censores - para o controle intelectual, do pensamento e da produção acadêmica.

Assim alicerçado, o Tribunal controlou a totalidade da vida portuguesa, como uma máquina burocrática com entrada de processos e de condenações que visava nutrir e manter sua engrenagem e, ao mesmo tempo, como protetor da vida religiosa, como doutrinador e único balizador da vida dos portugueses. Pode-se dizer, ainda, a partir da leitura da obra, que o Tribunal foi um sistema híbrido, estruturalmente racional em seus aspetos formais-legais e irracional por sua motivação dogmática e modo cruel de dominação da vida social, política e cultural portuguesa, cujas marcas e inspiração se fizeram sentir mesmo depois de sua extinção.

Rita Ribeiro Voss Universidade Federal de Pernambuco - UFPE ritaribeirovoss@uc.pt 